\title{
Trigger Point Release versus Instrument Assisted Soft Tissue Mobilization on Upper Trapezius Trigger Points in Mechanical Neck Pain: A Randomized Clinical Trial
}

\author{
MOHAMED N.H. ABDELHAMID, M.Sc.*; ENAS F. YOUSSEF, Ph.D.*; \\ AHMAD H. AZZAM, M.D.** and MAHA M. MOHAMMED, Ph.D.*
}

The Department of Physical Therapy for Musculoskeletal Disorders and its Surgery*, Faculty of Physical Therapy, Cairo University and Orthopaedic Surgery \& Traumatology**, Faculty of Medicine, Cairo University

\begin{abstract}
Background: Mechanical neck pain is a widespread significant health problem with a huge burden on the individual and economy. Finding a noninvasive effective treatment that's non exhaustive for the therapist and non painful for the patient is highly needed.
\end{abstract}

Aim of Study: This study investigated and compared the effects of instrument assisted soft tissue mobilization (IASTM) using $\mathrm{m} 2 \mathrm{t}$ blade and trigger point release (TPR) in terms of neck lateral flexion and rotation range of motion on upper trapezius (UT) myofascial trigger points (MTrPs) in mechanical neck pain.

Methods: Forty patients between 18 and 55 years were randomized to one either group A or B. Group A received one session of TPR and passive stretching while group B received one session of IASTM using M2t blade and passive stretching. Tape measurement was used to evaluate patients pretreatment, post treatment and at follow-up.

Results: Within group analysis, there was a significant increase in neck lateral flexion and rotation at immediate post treatment and at follow-up in both groups $(p<0.001)$. Between group analysis, there was with no significant difference in lateral flexion and neck rotation $(p>0.05)$

Conclusion: IASTM using M2t blade and TPR were effective in treating patients with mechanical neck pain and UT MTrPs.

Key Words: IASTM - Trigger point release - Mechanical neck pain - M2t blade - Neck-Myofascial trigger points.

\section{Introduction}

MECHANICAL neck pain is a general neck and/or shoulder type of pain that arises from maintained

Correspondence to: Dr. Mohamed N.H. Abdelhamid, The Department of Physical Therapy for Musculoskeletal Disorders and its Surgery, Faculty of Physical Therapy, Cairo University mechanical stresses with no clear etiological background [1]. It showed a one year prevalence of $16.7 \%$ to $75.1 \%$ with a mean of $37.2 \%$ [2].

Myofascial trigger points (MTrPs) are tender hypersensitive points distributed over a taut band of a muscle. MTrPs from head, neck and shoulder muscles play an important role in the genesis of mechanical neck pain [3]. Persistent MTrPs in the neck and shoulder muscles can result in a variety of symptoms as neck and shoulder pain, abnormal sensation, loss of range of motion, vertigo and autonomic dysfunction and disability [4-7].

Various methods of treatment were used to treat this condition including pharmacotherapy and Physical therapy. Pharmacotherapy included non steroidal anti-inflammatory drugs, botulinium toxin injections, anticonvulsants, muscle relaxants and etc. Physical therapy treatment methods included exercise, trigger point release, dry needling, ultrasound, laser and etc. [8].

Trigger point release (TPR) is a non invasive treatment that applies a continuous gradually increasing perpendicular compressive force over MTrP for 90 seconds in order to reverse its process of formation and also through reactive hyperemia or spinal reflex mechanism [9]. The positive effects of TPR were proved in many studies [10,11,12]. Some disadvantages of TPR as therapist's hand overloading and technique exertion, other methods are introduced [13].

One of these methods is Instrument assisted soft tissue mobilization (IASTM). M2t blade is a multifunctional instrument invented by Adam Bro- 
ger that is reasonable in price and has many planes that can be used in treatment. Its efficiency in improving patients symptoms was proven through many studies $[\mathbf{1 4 , 1 5}]$.

The aim of this study was to investigate and compare the effects of IASTM using m2t blade and TPR in terms of Pressure pain threshold (PPT) and pain level, neck function, neck lateral flexion and rotation on upper trapezius (UT) MTrPs in mechanical neck pain. Finding an effective, time consuming, non exhaustive method of treatment for patients with mechanical neck pain was a target. We hypothesized the non significance of either treatment protocol and the presence of non significant difference between them.

\section{Subjects and Methods}

Study design:

A Double blinded randomized clinical trial where an independent blinded assessor unaware about the treatment procedures while the primary investigator who provided physical therapy treatments was blinded about the assessment results. Sample size calculation was performed prior to

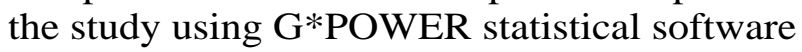
(version 3.1.9.2) [F tests-Repeated measures, between factors, $\alpha=0.05, \beta=0.2$, and large effect size $=0.4]$ and revealed that the appropriate required sample size was 40 .

\section{Subjects:}

Fifty male and female patients between 18 and 55 with mechanical neck pain responded to recruitment flyers at Faculty of Physical Therapy Clinic during November and December 2019.

Inclusion criteria was (1) Male and female participants between 18-55 years old (2) Mechanical neck pain localized to cervical and periscapular region (3) At least one trigger point and (4) Daily use computers for two hours [7,10,11,16,17].

Patients were excluded if they had any specific neck pathology as radiculopathy, rheumatoid arthritis and systemic diseases [16], sensory problems at mid or upper back [18], a tendency to hemorrhage $[\mathbf{1 6 , 1 9 ]}$ and history of head and upper trunk trauma or surgery [10].

All assessment and treatment procedures were provided at the Faculty of Physical Therapy Clinic. See Fig. (1) for a flow chart of the recruitment and retention of patients.
Total evaluated patient for eligibility $=50$ patients

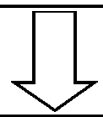

Excluded patient by refusal to participate on all phases of treatment $=5$ patients, by Age $=3$ patients above $55 \mathrm{Y}$ and by specific cause of pain $=2$ patients ( 2 patients have disc related symptoms with upper limb numbness)

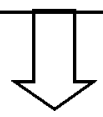

Forty patients with mechanical neck pain presented with upper trapezius trigger points were recruited for the clinical trial

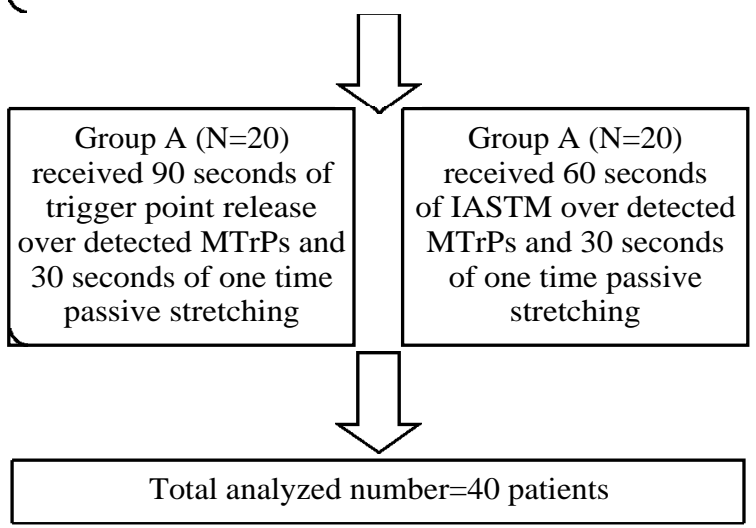

Fig. (1): The flow diagram of patients recruitment.

Our protocol was approved by the Ethical Committee Board, Faculty of Physical Therapy, Cairo University. All Patients who fulfilled the entry criteria signed consent forms after explaining the whole procedures and were informed that the recorded data would be submitted for publication.

\section{Examination procedures:}

Assessment was done by a blind assessor who is a physical therapist with 7 years of experience. Assessment was pretreatment, immediately post treatment and at the end of the one week followup. No changes occurred at trial outcomes since the start of study.

\section{Detection of MTrPs:}

We used a recommended diagnostic criterion to find MTrPs which is: (1) The presence of a palpable taut band in the skeletal muscle, (2) The presence of a hypersensitive spot in the taut band, (3) Local twitch response provoked by snapping palpation, (4) Production of a typical referred pain pattern in response to the compression of tender spots and (5) Spontaneous presence of the typical referred pain pattern. If only four points of criteria were satisfied, the trigger points were considered latent, and if all were included, the trigger points were considered active [20]. 
Cervical side bending and rotation range of motion:

Tape measure is a simple and available tool to measure cervical range of motion. It correlated well with a universal goniometer with the best results for flexion and extension [3]. It had acceptable test-retest reliability in measuring cervical active range of motion except for left lateral flexion. Its Concurrent validity for measuring cervical AROM were weak but statistically significant [1].

For measuring neck lateral bending and rotation, the individual sat with relaxed shoulders and the

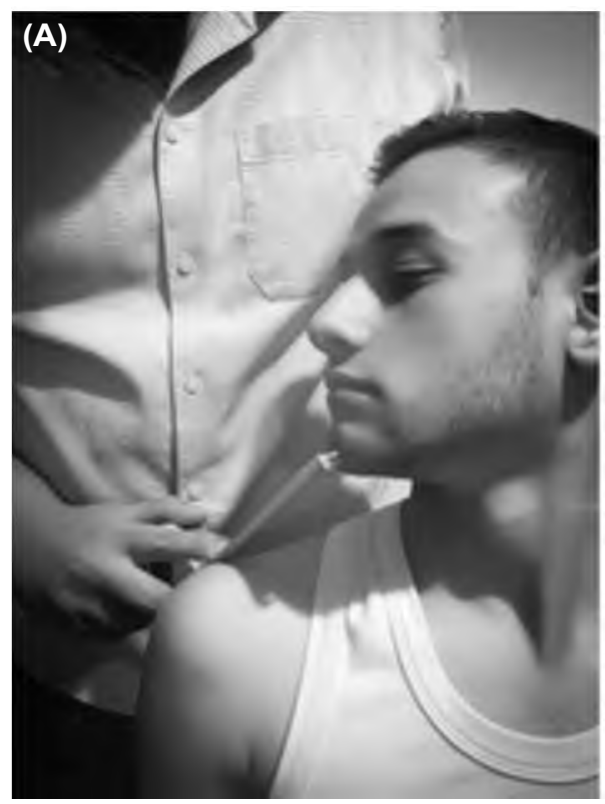

trunk well supported with hands placed on the thighs and feet flat on the floor. Markings are placed on mastoid and lateral tip of acromial process for lateral bending and on the tip of the chin and the acromial process for rotation. All movements were done without compensating in other planes.

For measuring lateral bending, the individual was asked to try to touch the ear to the shoulder then measure the distance between markings. For rotation, the individual was asked to turn the head as far as possible then measured the distance between markings (Figs. 2A,B) [30].

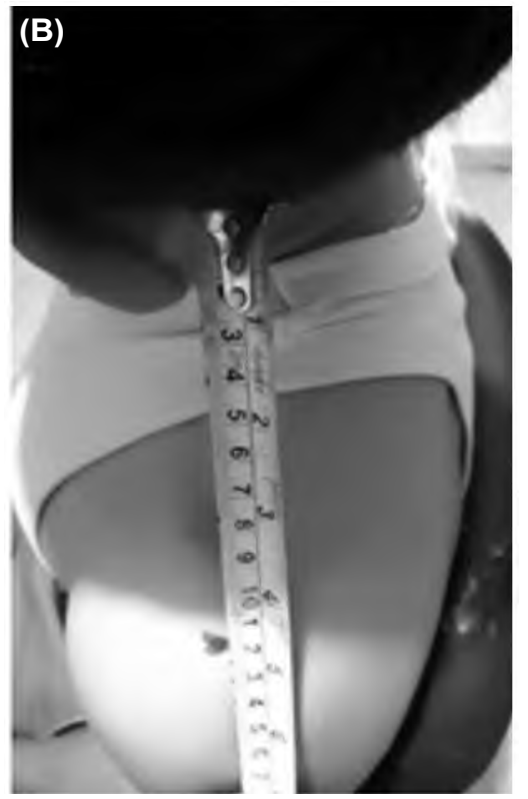

Fig. (2): Assessment of neck rotation (A), Lateral Flexion (B).

\section{Treatment procedures:}

By the end of the assessment procedures, patients were randomized to group A $(n=20)$ or $B$ $(n=20)$ based on Covariate adaptive randomization using randomization software graphpad QuickCalcs. This process of using software and allocation was done by a research assistant. Treatment was provided by the primary investigator who is a physical therapist with 8 years of experience and blinded about assessment results. Each patient received treatment in a room of comfortable temperature and the area of treatment was uncovered for intervention. Group A received one session of TPR and passive stretching. The therapist applied a continuous gradually increasing perpendicular thumb pressure to the MTrP until pain arises. Then, the pressure was maintained until $50 \%$ reduction in pain as perceived by the patient subsequently the pressure was increased and the process was repeated for 90 seconds $[\mathbf{7 , 1 7 , 2 4 ]}$.
Group B received one session consisted of IASTM using $\mathrm{m} 2 \mathrm{t}$ blade and passive stretching while in prone position. An emollient was used to prevent skin irritation afterwards the therapist applied one minute of IASTM by the $\mathrm{m} 2 \mathrm{t}$ blade (Fanning strokes at 45 degrees to the muscle fibers) over UT using treatment planes 1 and 2 [25].

Passive stretching was perfomed with one hand on the occiput and the other hand stabilized the shoulder. The participant's head was passively placed into flexion, contralateral side-bending and ipsilateral rotation then stressed the muscle barrier and while depressing the shoulder. Stretching was done for 30 seconds once [26].

\section{Statistical analysis:}

$t$-test was conducted for comparison of the age and Chi squared test was conducted for comparison of sex distribution between groups. The normality of data was assessed using Shapiro-Wilk test and 
Levene's test to assess the equality of variances. Mixed MANOVA was conducted to compare time effect (pre, immediate and follow-up) and treatment effect (between groups), plus the interaction between time and treatment on mean values of neck lateral flexion and rotation. Multiple post-hoc tests were conducted using the Bonferroni correction. Statistical measures were performed through the statistical package for social studies (SPSS) version 22. The level of significance for all statistical tests was set at $p<0.05$.

\section{Results}

Forty subjects participated in the study and received treatment during the period from January to March 2020. The mean \pm SD of the group A was $30.7 \pm 11.93$ years and that of the group B was $30.15 \pm 11.43$ years. Ten patients were excluded pre interventions with no dropouts occurred. There was no significant difference in the basic characteristics of participants between both groups $(p<0.05)$ (Table 1). Mixed MANOVA revealed a significant interaction of treatment and time $(\mathrm{F}=$ 3.97, $p=0.002$ ). There was a significant main effect of time $(\mathrm{F}=28.77, p=0.001)$ and significant main effect of treatment $(\mathrm{F}=2.76, p=0.02)$. The trial completed successfully and no adverse events or harms were reported (Table 1).

\section{Between group comparison:}

There was no significant difference between groups in variables pre treatment $(p>0.05)$. There was no significant difference in lateral flexion and neck rotation between groups at immediate post treatment and follow ( $p>0.05)$ (Table 2).

\section{Within group comparison:}

There was a significant increase in lateral flexion and neck rotation at immediate post treatment and follow-up in comparison to pretreatment in group A and B $(p<0.001)$. There was no significant difference between immediate post treatment and follow-up in group A $(p>0.05)$, while there was a significant increase in PPT and a significant decrease VAS and lateral flexion in group B at followup compared with that at immediate post treatment $(p<0.01)$ (Table 2).

Table (1): Basic characteristics of participants.

Group A Group B $p$-value

Age, mean $\pm(S D)$, years $30.7 \pm 11.9330 .15 \pm 11.430 .88$

$\operatorname{Sex}, n(\%)$ :

$\begin{array}{llll}\text { Females } & 9(45 \%) & 7(35 \%) & 0.51\end{array}$

Males $\quad 11(55 \%) 13(65 \%)$

SD: Standard deviation. $\quad p$-value: Level of significance.

Table (2): Mean neck lateral flexion and rotation and NDI in the group A and B at pre treatment, immediate post treatment and follow-up.

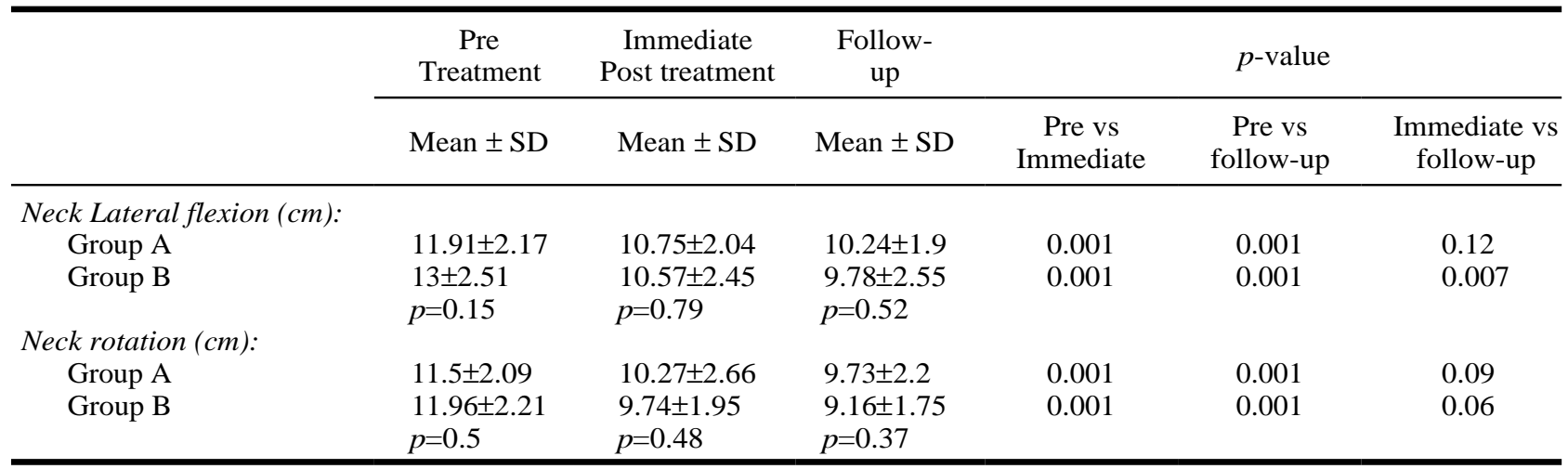

SD: Standard deviation. $\quad p$-value: Level of significance.

\section{Discussion}

This is the first study to investigate and compare the effects of IASTM using $\mathrm{m} 2 \mathrm{t}$ blade and TPR in term of neck lateral flexion and rotation range of motion on UT MTrPs in mechanical neck pain.

Both groups showed significant effects in improving range of motion. There was no significant difference in neck lateral flexion and rotation between the two groups.
The improvements in patients who received IASTM by M2t blade could be explained through loosening and removal of scar tissues and adhesions secondary to skin scraping which decreased soft tissue consistency and improved range of motion. It also induced vasodilation response and microvascular hemorrhage; so provided oxygen, nutrients and removed metabolic end products and inflammatory mediators which improved pain level and ppt. Fibroblastic activity and its proliferative invasion were boosted leading to better collagen dep- 
osition, maturation and consequently the healing process was enhanced [27-30].

It was also stated the role of Manual muscle treatment as anti inflammatory through increasing anti inflammatory mediators [31]. The results of IASTM using M2t blade were in agreement with many studies that showed significant effects in decreasing pain level, increasing functional level, PPT and range of motion [14,15,25,32].

The explanation of the effects of TPR was always a matter of debate. Simons, stated that TPR places a compressive force on an inflated ballon as a representation to MTrP that makes the contraction knot wider and shorter similar to normal shape and alignment [3]. The positive effects produced post compression supplied blood supply providing with nutrition, oxygen and all cellular energy demands needed in the form reactive hyperemia or secondary to spinal reflex mechanism [9]. These mechanisms optimize the length and extensibility of the muscle fibers with reversing the effects of the energy crisis which improve the range of motion.

The results of TPR are in agreement with many studies that showed a significant effect on increas-

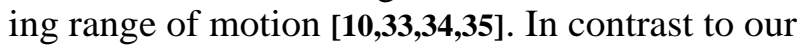
results, Gemmel et al., 2008 showed that there was no significant difference between groups in regard to secondary outcomes. Clinical improvement is the primary technique instead of statistical significance favouring ischemic compression.

\section{Limitations:}

Some limitations are present in our study. The study didn't include a control group and there was no long term follow-up so the long term effects of treatment weren't investigated in our study.

\section{Conclusion:}

IASTM using M2t blade and TPR were effective in treating patients with mechanical neck pain and UT MTrPs.

\section{References}

1- CASTALDO M., GE H.Y., CHIAROTTO A., VILLAFANE J.H. and ARENDT-NIELSEN L.: Myofascial trigger points in patients with whiplash-associated disorders and mechanical neck pain. Pain Medicine, 15 (5): 8429, 2014.

2- FEJER R., KYVIK K.O. and HARTVIGSEN J.: The prevalence of neck pain in the world population: A systematic critical review of the literature. European Spine Journal, 15 (6): 834-48, 2006.

3- SIMONS D.G.: Understanding effective treatments of myofascial trigger points. Journal of Bodywork and movement therapies, 6 (2): 81-8, 2002.
4- HANTEN W.P., OLSON S.L., BUTTS N.L. and NOWICKI A.L.: Effectiveness of a home program of ischemic pressure followed by sustained stretch for treatment of myofascial trigger points. Physical Therapy, 80 (10): 9971003,2000

5- RUDIN N.J.: Evaluation of treatments for myofascial pain syndrome and fibromyalgia. Current Pain and Headache Reports, 7 (6): 433-42, 2003.

6- LUCAS N., MACASKILL P., IRWIG L., MORAN R. and BOGDUK N.: Reliability of physical examination for diagnosis of myofascial trigger points: A systematic review of the literature. The Clinical Journal of Pain, 25 (1): 80-9, 2009.

7- ZIAEIFAR M., ARAB A.M., KARIMI N. and NOURBAKHSH M.R.: The effect of dry needling on pain, pressure pain threshold and disability in patients with a myofascial trigger point in the upper trapezius muscle. Journal of bodywork and movement therapies, 18 (2): 298-305, 2014.

8- DESAI M.J., SAINI V. and SAINI S.: Myofascial pain syndrome: A treatment review. Pain and therapy, 2 (1): 21-36, 2013.

9- HOU C.R., TSAI L.C., CHENG K.F., CHUNG K.C. and HONG C.Z.: Immediate effects of various physical therapeutic modalities on cervical myofascial pain and triggerpoint sensitivity. Archives of physical medicine and rehabilitation, 83 (10): 1406-14, 2002.

10- OLIVEIRA-CAMPELO N.M., de MELO C.A., ALBURQUERQUE-SENDÍN F. and MACHADO J.P.: Short-and medium-term effects of manual therapy on cervical active range of motion and pressure pain sensitivity in latent myofascial pain of the upper trapezius muscle: A randomized controlled trial. Journal of manipulative and physiological therapeutics, 36 (5): 300-9, 2013.

11- KASHYAP R., IQBAL A. and ALGHADIR A.H.: Controlled intervention to compare the efficacies of manual pressure release and the muscle energy technique for treating mechanical neck pain due to upper trapezius trigger points. J. Pain Res., 11: 3151-3160, 2018.

12- SHARIFULLAH M., SAJJAD A.G., MOBEEN A., TARIQ I., KHAN A. and DARAIN H.: Comparison of sustained pressure vs ischemic compression on trigger points in chronic myofacial pain management. Khyber Medical University Journal, 10 (2), 2018.

13- TABATABAIEE A., EBRAHIMI-TAKAMJANI I., AHMADI A., SARRAFZADEH J. and EMRANI A.: Comparison of pressure release, phonophoresis and dry needling in treatment of latent myofascial trigger point of upper trapezius muscle. Journal of Back and Musculoskeletal Rehabilitation, 32 (4): 587-94, 2019.

14- NAIK V., KOYANDE S. and SHAIKH R.: Comparative study between the effect of myofascial release using M2T Blade and kinesiotape on recreational badminton shoulder pain subjects: a randomised clinical trial. International Journal of Medical Research \& Health Sciences, 6 (5): 1-6, 2017.

15- NAIK V., SHAIKH R. and KOYANDE S.: Immediate effects of M2T blade on pain and range of motion in recreational badminton shoulder pain subjects: A pilot study.Journal of medical science and clinical research, 18: 30, 2016. 
16- BLIKSTAD A. and GEMMELL H.: Immediate effect of activator trigger point therapy and myofascial band therapy on non-specific neck pain in patients with upper trapezius trigger points compared to sham ultrasound: A randomised controlled trial. Clinical Chiropractic, 11 (1): 23-9, 2008.

17- GEMMELL H., MILLER P. and NORDSTROM H.: Immediate effect of ischaemic compression and trigger point pressure release on neck pain and upper trapezius trigger points: A randomised controlled trial. Clinical Chiropractic, 11 (1): 30-6, 2008.

18- GULICK D.T.: Instrument-assisted soft tissue mobilization increases myofascial trigger point pain threshold. Journal of bodywork and movement therapies, 22 (2): 341-5, 2018.

19- LAUCHE R., CRAMER H., HOHMANN C., CHOI K.E., RAMPP T., SAHA F.J., MUSIAL F., LANGHORST J. and DOBOS G.: The effect of traditional cupping on pain and mechanical thresholds in patients with chronic nonspecific neck pain: a randomized controlled pilot study. Evidence-Based Complementary and Alternative Medicine, 429718, 2012.

20- SIMONS D.G., TRAVELL J.G. and SIMONS L.S.: Travell \& Simons' myofascial pain and dysfunction: Upper half of body. Lippincott Williams \& Wilkins, 1999.

21- ASHA S.E., PRYOR R.: Validation of a method to assess range of motion of the cervical spine using a tape measure. Journal of Manipulative and Physiological Therapeutics, 36 (8): 538-45, 2013.

22- ADEGOKE B.O., OFFIAH M.N., OKOYE E.C. and AKOSILE C.O.: Intra-Rater reliabilities and concurrent validity of the universal goniometer and tape measure for measuring cervical active range of motion. Journal of Musculoskeletal Research, 18 (01): 1550005, 2015.

23- NORKIN C.C. and WHITE D.J.: Measurement of joint motion: A guide to goniometry. FA Davis, Nov. 18, 2016.

24- FERNÁNDEZ-DE-LAS-PEÑAS C., ALONSO-BLANCO C., FERNÁNDEZ-CARNERO J. and MIANGOLARRAPAGE J.C.: The immediate effect of ischemic compression technique and transverse friction massage on tenderness of active and latent myofascial trigger points: A pilot study. Journal of Bodywork and Movement Therapies, 10 (1): 3-9, 2006.

25- MOTIMATH B. and AHAMMED N.: Comparative study on effectiveness of trigger point release versus cervical mobilization in chess players with mechanical neck pain. International Journal of Physical Education, Sports and Health, 4 (3): 207-211, 2017.
26- HANNEY W.J., PUENTEDURA E.J., KOLBER M.J., LIU X., PABIAN P.S. and CHEATHAM S.W.: The immediate effects of manual stretching and cervicothoracic junction manipulation on cervical range of motion and upper trapezius pressure pain thresholds. Journal of Back and Musculoskeletal Rehabilitation, 30 (5): 1005-13, 2017.

27- DAVIDSON C.J., GANION L.R., GEHLSEN G.M., VERHOESTRA B.E., ROEPKE J.E. and SEVIER T.L.: Rat tendon morphologic and functional changes resulting from soft tissue mobilization. Medicine and science in sports and exercise, 29 (3): 313-9, 1997.

28- GEHLSEN G.M., GANION L.R. and HELFST R.O.: Fibroblast responses to variation in soft tissue mobilization pressure. Medicine and science in sports and exercise, 31 (4): 531-535, 1999.

29- HAMMER W.I.: The effect of mechanical load on degenerated soft tissue. Journal of Bodywork and Movement Therapies, 12 (3): 246-56, 2008.

30- BAKER R.T., NASYPANY A., SEEGMILLER J.G. and BAKER J.G.: Instrument-assisted soft tissue mobilization treatment for tissue extensibility dysfunction. International Journal of Athletic Therapy and Training, 18 (5): 16-21, 2013.

31- STANDLEY P.: Biomechanical strain regulation of human fibroblast cytokine expression: an in vitro model for myofascial release. In First International Fascia Research Congress, 2007.

32- EL-HAFEZ H.M., HAMDY H.A., TAKLA M., AHMED S.E., GENEDY A.F. and AL SHAYMAA S.: Instrumentassisted soft tissue mobilisation versus stripping massage for upper trapezius myofascial trigger points. Journal of Taibah University Medical Sciences, 15 (2): 87-93, 2020.

33- AGUILERA F.J., MARTÍN D.P., MASANET R.A., BOTELLA A.C., SOLER L.B. and MORELL F.B.: Immediate effect of ultrasound and ischemic compression techniques for the treatment of trapezius latent myofascial trigger points in healthy subjects: A randomized controlled study. Journal of manipulative and Physiological Therapeutics, 32 (7): 515-20, 2009.

34- KANNAN P.: Management of myofascial pain of upper trapezius: A three group comparison study. Global Journal of Health Science, 4 (5): 46-52, 2012.

35- DALAL P. and KAGE V.: Comparison of Ischaemic Compression, Myofascial Release and Bowen S Technique In Non Specific Neck Pain-A Randomized Clinical Trial. Indian Journal of Applied Research, 10 (1), 2020. 


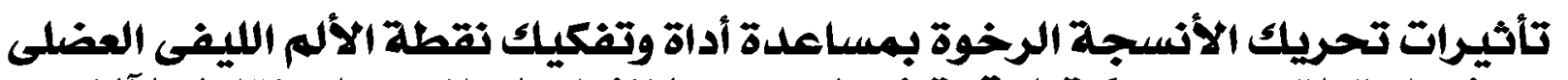

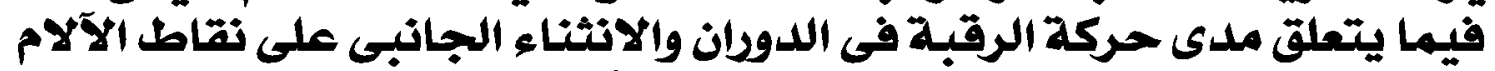

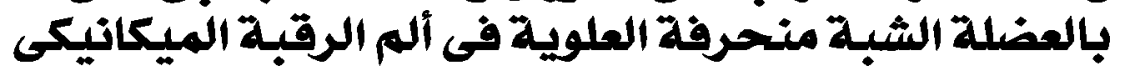

الخفلفية: ألم الرقبة الميكانيكى هو مشكلة صحية منتشرة وهامة ذات عبئ كبير على الفرد، المجتمع والآقتصاد . أن إيجاد وسيلة علاجية

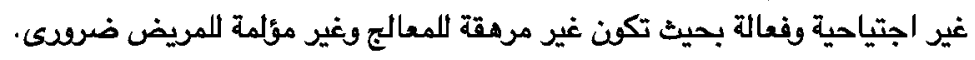

الأهداف: هذه الدراسة تصقق وتقاض تأثيرات تصريك الأنسجة الرخوة بمساعدة أداة وتفكيك نقطة الألم الليفى العضلى فيما يتعلق مدىى

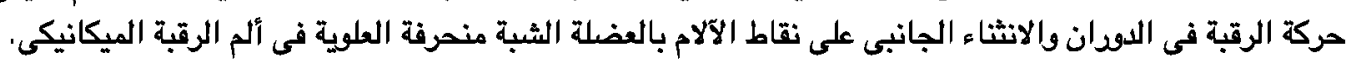

الوسائل : أربعون مريض بين الثامنة عشر والخامسة والخمسين تم توزيعهم بشكل عشوائى إلى أى من الجروب أ أو ب. جروب أ أ تلقى جلسة

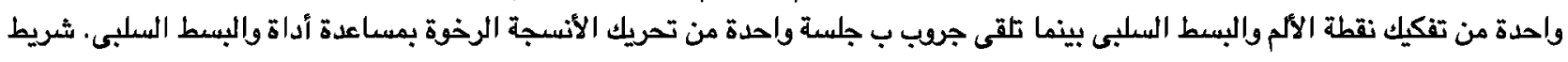

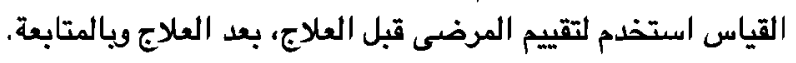

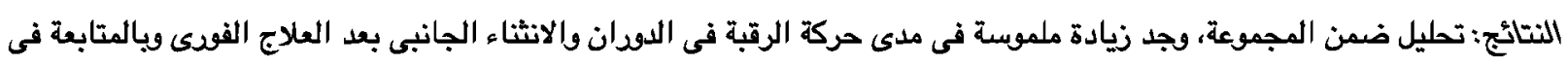

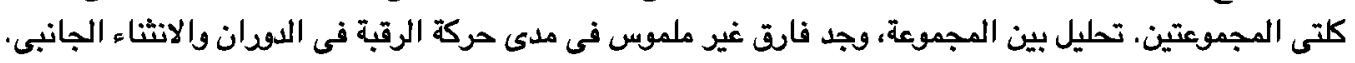

الاستتاج: تصريك الأنسجة الرخوة بمساعدة أداة وتفكيك نقطة الألم هما فعاليان فى علاج مرضى ألم الرقبة الميكانيكى ونقاط الآلام الليفية

العضلية بالعضلة الثبة منحرفة. 